\title{
Accessibility Analysis of Healthcare Delivery System within Enugu Urban Area Using Geographic Information System
}

\author{
Ifeanyi R. Ejiagha ${ }^{1}$, Johnbusco C. Ojiako ${ }^{2}$, Chijioke G. Eze ${ }^{3}$ \\ ${ }^{1}$ Department of Surveying and Geoinformatics, Akanu Ibiam Federal Polytechnic, Afikpo, Nigeria \\ ${ }^{2}$ Department of Surveying and Geoinformatics, Nnamdi Azikiwe University, Awka, Nigeria \\ ${ }^{3}$ Joint Operations Centre, Defence Headquarters, Abuja, Nigeria \\ Email: anyiejiagha@yahoo.com, ojiakochibueze@yahoo.com,chijiokeze@yahoo.com
}

Received April 22, 2012; revised May 22, 2012; accepted June 20, 2012

\begin{abstract}
The problem of accessibility of health institution, with respect to the available facility to serve the entire population leaving in an area, can be solved using GIS. This paper presents an analysis on accessibility of healthcare facilities in Enugu urban area in a GIS environment. This was achieved through acquisition of a base map of Enugu State showing geographic extent of Enugu Urban, determining the geometric positions of health institutions in Enugu urban using handheld GPS, Creation of a spatial database of existing healthcare facilities and demonstrating through various analyses the potentials of GIS in measurement of accessibility to healthcare facilities in Enugu urban Area. The analysis includes network analysis, used to determine the closeness of a facility and shortest route to these healthcare facilities. ARCGIS 9.3 was the main software used. This was supported by Geocal for coordinate conversion and Microsoft office packages. The result of the study showed the spatial distribution of health institutions, closest facilities in case of emergency and route to those health institutions within Enugu urban Area. It was noticed that most of the healthcare facilities were located within Enugu North local government area (LGA). Other settlements and LGAs had fewer healthcare facilities. Areas deprived of healthcare facility were also identified. Routes and closest facilities to those deprived areas were identified in the settlements/area. The analysis showed the efficacy of GIS in determining accessibility of healthcare institutions in Enugu urban area. The study is thus, recommended as a spatial decision support system for decisions regarding spatial accessibility of healthcare facilities in an urban area.
\end{abstract}

Keywords: GIS; Accessibility; Database; Healthcare Facilities; District Health System

\section{Introduction}

The maintenance of good health and easy access to adequate healthcare has been a challenge to mankind. This challenge has led to attempts by government(s) and nongovernmental outfits to setup public healthcare facilities in various parts of the world. Public healthcare is regarded as the basic form of healthcare as it provides the least expensive source of medical treatment to the greater population of people resident in any given area (Effiong, 2010) [1]. Healthcare delivery system in Nigeria as a sub Saharan African Country comprises of the primary, secondary and tertiary healthcare facilities (Uzochukwu et al., 2009) [2]. The health policy in Nigeria has been influenced by different local and regional factors that affect the quality and quantity present in one location (Uzochukwu et al., 2009) [2]. This has led to a total decay and neglect in the primary healthcare delivery system.

In an effort to support the Nigerian national health policy on primary healthcare delivery system, the Enugu State government introduced District Health System
(DHS) in 1999. This is a form of decentralization of the health sector, delivered under a structured management system (District Health Management Team) which integrates the primary and secondary healthcare delivery to accommodate the rural populace. The DHS in Enugu state has gained success in the management, preventive, treatment of various ailments and sharing of information. A major policy trust of the DHS, is the knowledge of the spatial distribution of the healthcare facilities and the population it serves. This is the first step in achieving an efficient healthcare delivery system. Therefore, the DHS with the state ministry of health in 2005 carried out a survey to map out the spatial distribution of all the healthcare facility in the state. In order to solve the problem of accessibility and location of these primary healthcare facilities, detailed records of the geographic locations and the population they serve were taken. Therefore, to determine accessibility to health facilities in Enugu Urban, accurate knowledge of the facilities and the spatial distribution is required (Eze, 2008) [3]. The GIS pro- 
vides a platform to assess the distribution and route to the health institutions.

The demand for healthcare services has increased over the years in Enugu urban area due to the growing population of the city. Healthcare facilities that were initially meant for two settlements are now being used by seventeen settlements of Enugu urban area. These has caused over utilization of public healthcare facilities and delays in accessing same. Another problem is congestions on routes in-and-out of these facilities due to traffic and economic activities associated with an urban area. In case of emergency, response to save life is very minimal because of no definite route to those healthcare facilities especially the specialist hospitals. The above mentioned problems lead to self medication, patronage of patent medicine dealers, infant and maternal mortality etc. In order to ameliorate the problems encountered in accessing good healthcare facilities, a GIS based technique was used to measure accessibility of the healthcare facilities in Enugu urban and to define shortest routes and closest facilities during emergencies. The current situation of healthcare delivery in Enugu urban leaves much to be desired. It is against this backdrop that the study which seeks to measure accessibility of healthcare facilities in Enugu urban area using GIS for proper analysis, management and utilization was carried out. The study highlighted the challenges healthcare services faced and will be limited to healthcare facility in Enugu urban.

\subsection{Study Area}

Enugu urban is the administrative capital of Enugu State, South East Nigeria. It is located within coordinates $6^{\circ} 22^{\prime} \mathrm{N}$ to $6^{\circ} 38^{\prime} \mathrm{N}$ and $7^{\circ} 28^{\prime} \mathrm{E}$ to $7^{\circ} 37^{\prime} \mathrm{E}$. Enugu urban area is made up of Enugu North, Enugu South and Enugu East local government areas (Figures 1 and 2). It has a combined population of 722,664 based on 2006 estimate (Fed. Gov. Gazette, 2007) [4]. Until now coal mining has been the mainstay of the city which is home to civil servants, traders, artisans and good number of farmers. The people are mainly Igbos in different settlements, layouts and housing estates (e.g. Abakpa Nike, Trans Ekulu, Emene, GRA, Iva valley, Ogui, Coal camp, Uwani, Akwunanaw, Independence layout, Ugbodogwu and Ugwu-Aaron). A sizeable number of non-Igbos are found in areas such as: Asata, Ama-hausa, Artisan and Garki. The major streets includes: Okpara Avenue, Chime Avenue, Emene road, Ogui road, Agbani road, Zik Avenue, Abakaliki road, Rangers Avenue, Presidential road, Nike road, Bisala road, Nkpokiti road. It is a commercial centre of sort, with its ever busy markets coming up every day.

\subsection{Basis for Measuring Healthcare Accessibility from GIS}

Accessibility to healthcare facilities in Enugu urban area

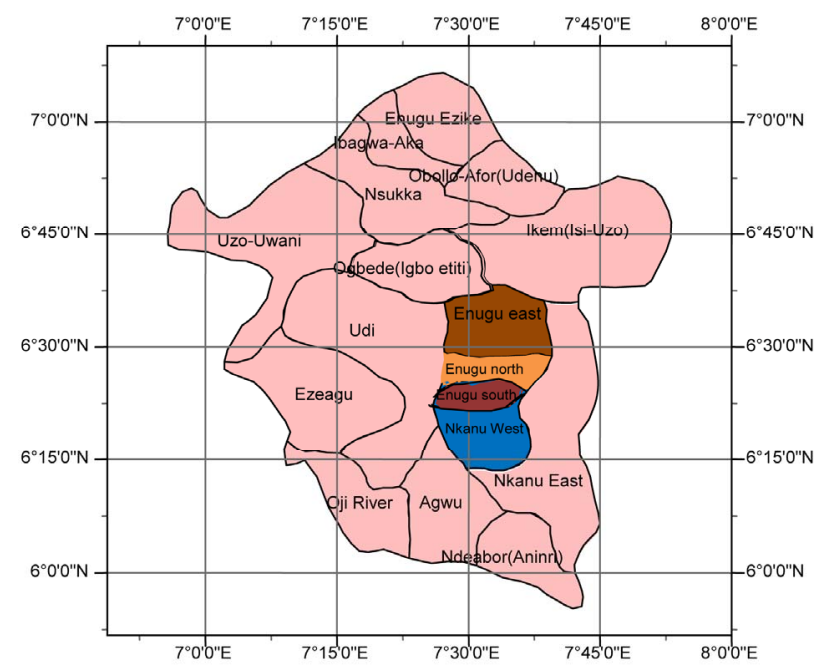

Figure 1. Map of Enugu state showing the three LGA of Enugu urban (study area) (Source: modified after Eze, 2008 [3]).

is very difficult because of population growth. This has resulted in over utilization of the existing public healthcare facilities within the urban centre because privately owned healthcare facilities are very expensive to access. A lot of challenges are experienced at these public healthcare facilities within the urban area. Yet there is still not an accepted and convincing way of measuring accessibility, functionality and spatial distribution of healthcare facility in Enugu urban area by the government. These are some of the reasons for quick spread of diseases, low response to emergencies and treatments, infant and maternal mortality, quackery, self medication, and patronage of patent medicine dealers within the urban centre. Therefore, to march the healthcare demand of Enugu urban area, a GIS based technique was developed to empirically and scientifically measure accessibility, proximity and spatial distributions of healthcare facilities. This is in order to solve the problems and challenges faced in this area.

\section{Methodology}

The various methods adopted for the study includes acquisition of data, geo-referencing, digitizing, spatial database building and GIS analysis.

\subsection{Data Acquisition}

This stage includes the planning stage, hardware and software requirements, primary data and secondary data acquisition.

\subsubsection{Planning Stage}

At this stage considerations were made on the hardware and software required for the study. Planning stage in- 


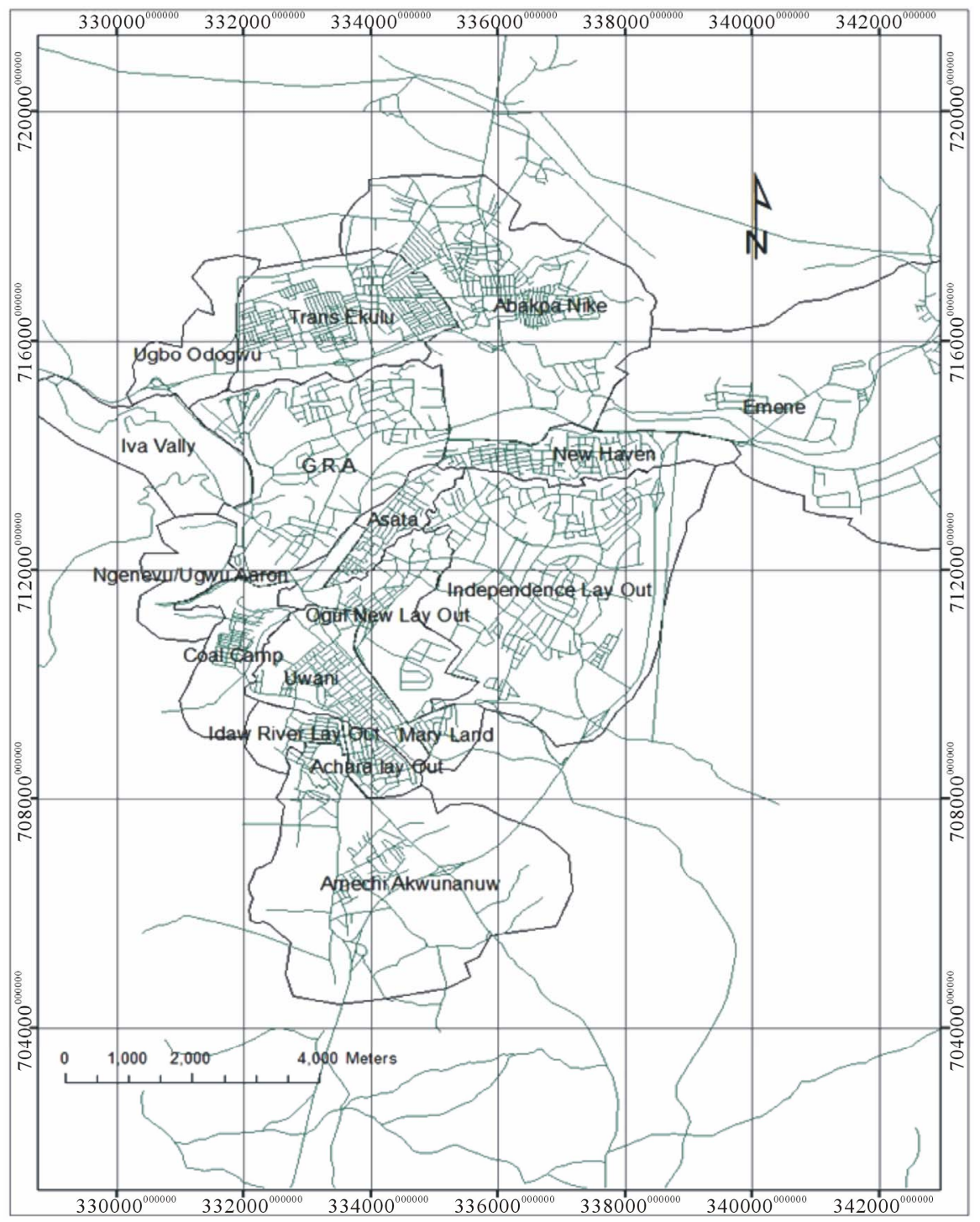

Figure 2. Map of Enugu urban area (study area) showing settlements.

volved consideration of the quality, quantity and type of data to be included in the database. It was decided based on the nature of the data and available time to acquire the following hardware and software tools for the study:

Hardware and software requirements (used) includes:

- A3 musket scanner.

- HP Compaq laptop with 120 GB of HDD, 2 GB of RAM, $1.87 \mathrm{GH}_{3}$ clock-speed, 32-bit operating system.

- Hand held G.P.S (Etrex H).

- HP DeskJet Printer (D1500 model).

- The principal software used for the study included an ARC GIS 9.3 version and Microsoft word 2007.

\subsubsection{Acquisition of Primary Dataset}

The primary dataset acquired through field visitation were:
- Geometric positions of healthcare institutions using hand held Global Positioning System (GPS).

- The attribute data of the healthcare institutions made up of non spatial descriptive information and also published/unpublished records kept by statutory bodies and organizations. The records were sourced from Enugu DHS, Enugu state Ministry of Health, LGAs within the Enugu urban centre and Ministry of lands and Survey.

\subsubsection{Acquisition of Secondary Dataset}

The secondary dataset needed were acquired from Enugu urban area map and Spot 5 satellite imagery of the same area. The secondary data were obtained through digitization of the map of Enugu urban and satellite imagery of Enugu urban area. The satellite imagery of Enugu was used to update the base map of Enugu urban area which 
was found to be very old and lacked in desired details.

\subsection{Geo-Referencing}

The secondary data set (satellite imagery and base map) acquired was first geo-referenced in order to make the computer accept the coordinate and treat the image as part or portion of earth surface. The processes involved using the handheld GPS to collect the geometric data of five road junctions. These geometric data was used to geo-reference the satellite imagery.

\subsection{Image Digitization}

The spot 5 satellite imagery of Enugu urban area was digitized in order to update the existing map of Enugu urban area which was found to be old. The map was last updated in 1986. In order to do this, shape files of the entities in the study area were first created in Arc-Catalogue. The shape files were added to the Arc Map environment for digitizing. The process of digitization involved the use of Editor Tool Bar to trace out all the features in the satellite imagery and other points of interest.

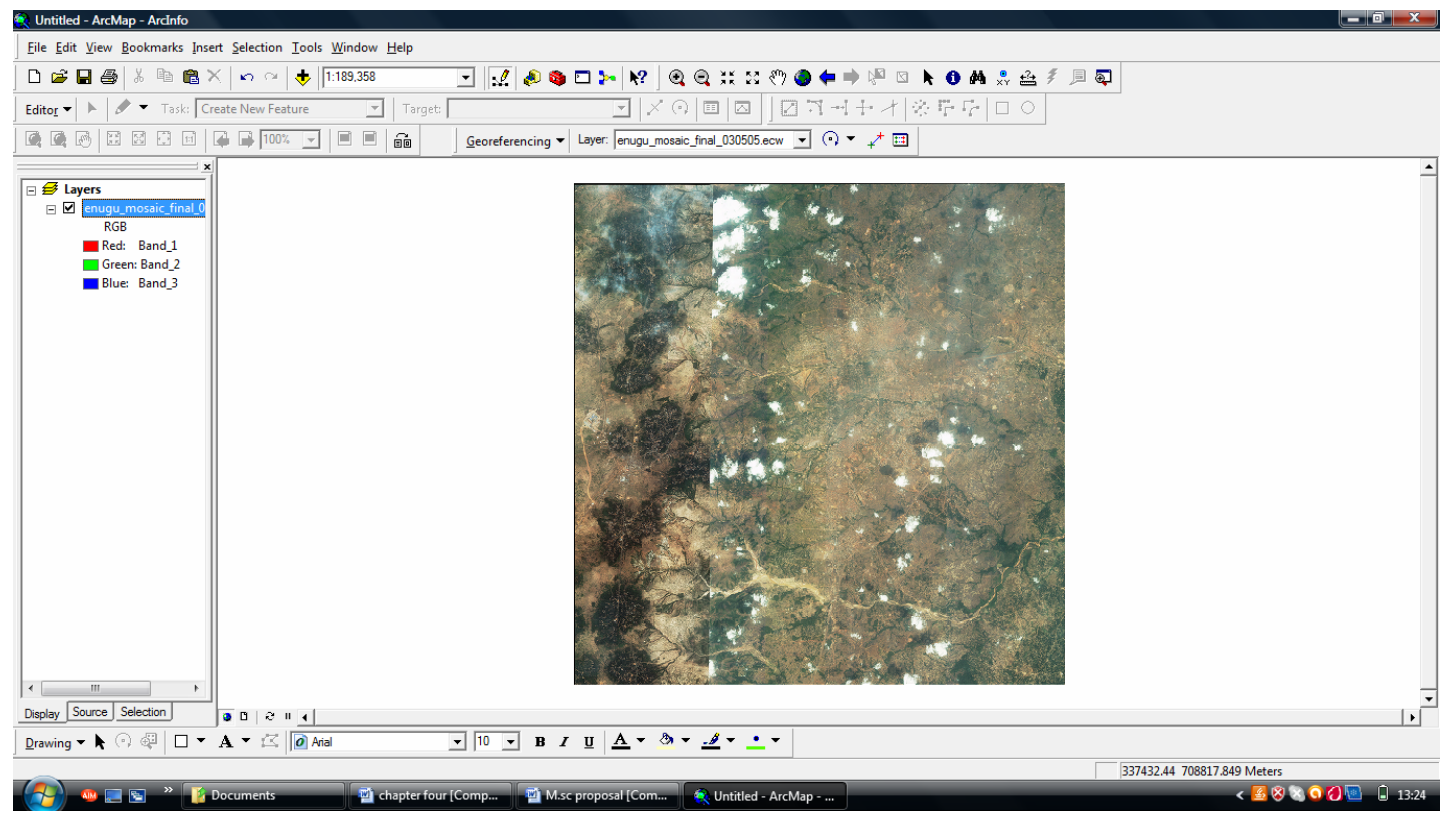

Figure 3. Spot 5 satellite imagery of the study area.

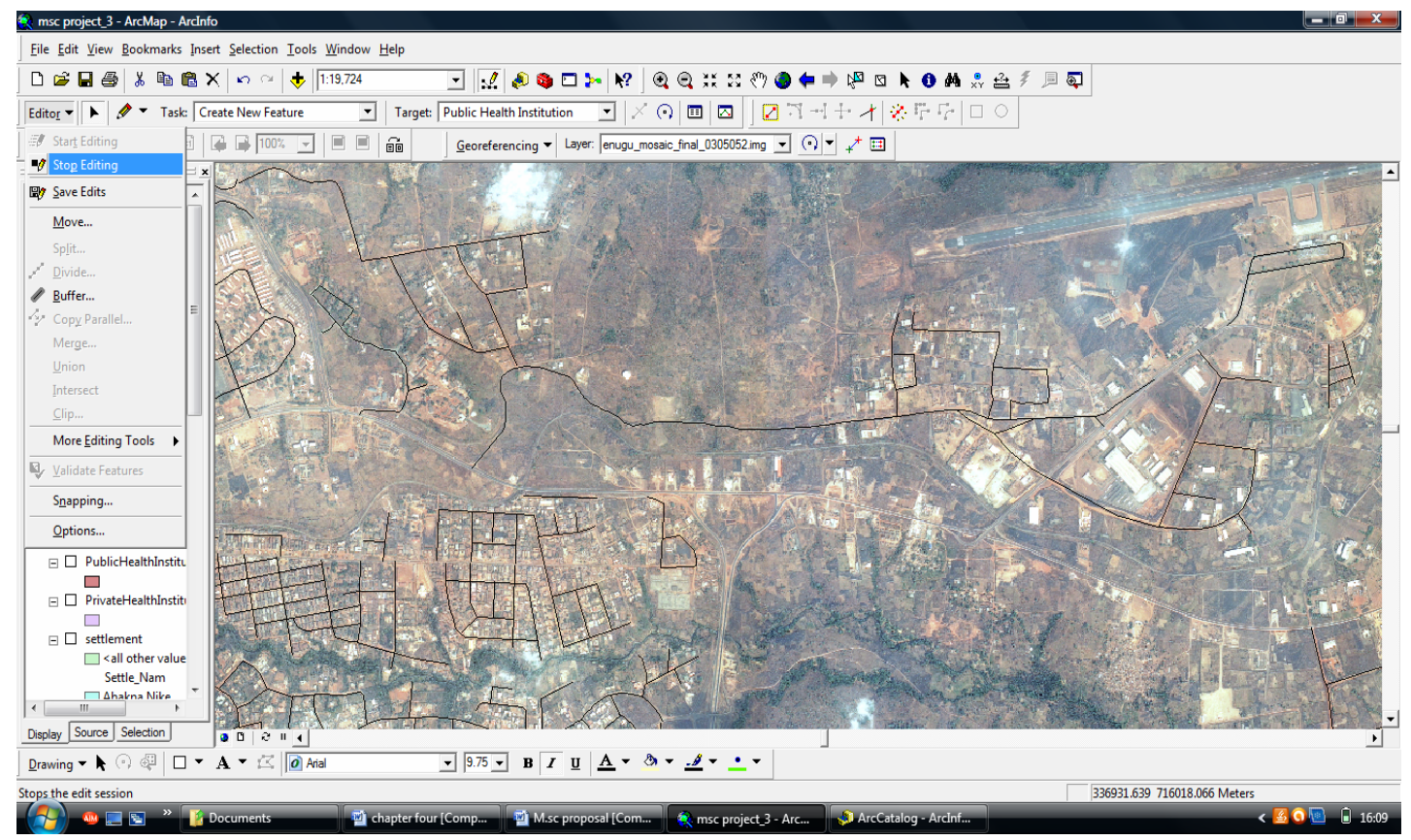

Figure 4. Digitization process of the satellite imagery of the study area. 


\subsection{Spatial Database Creation}

The entire attribute data gathered [through Oral interviews and from records of ministries, District Health System (DHS), National Population Commission (NPC) et al] was used for the basis of GIS database creation and database modelling. Some of these attributes were created digitally using spreadsheets. The DBMS is the platform on which the databases were modelled internally and linked using the in-built attribute table capabilities in
ARCGIS 9.3 environment. In order to create and model the database, tables were created and linked to ARCGIS shape file using geo-relational technology. The database designing process used in the study involves three stages: Conceptual design, Logical design and Physical design.

\subsection{GIS Analysis}

This comprises of various analysis performed in order to measure accessibility of these healthcare facilities in

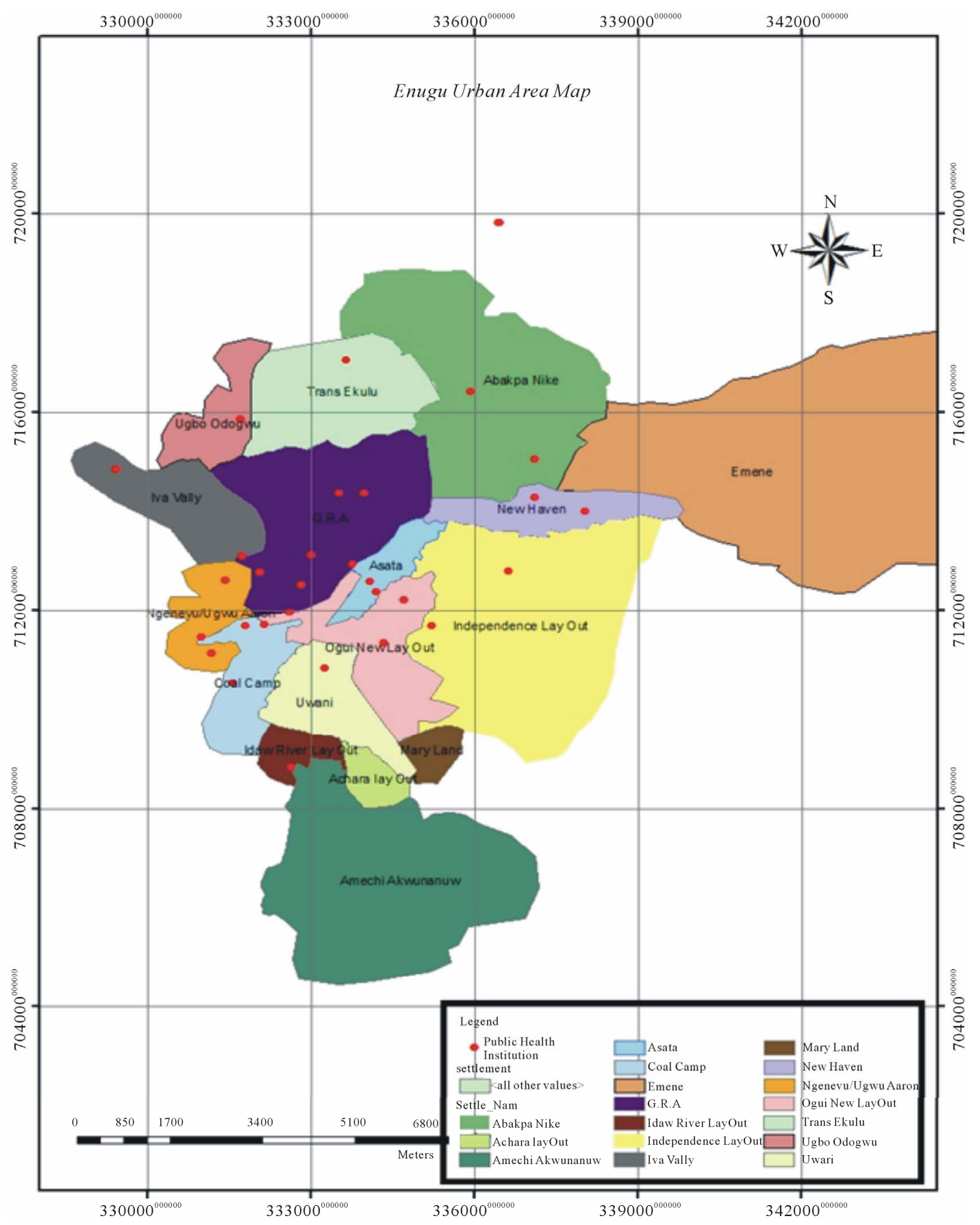

Figure 5. Digital map showing spatial distribution of public health institutions in Enugu urban area. 
Enugu urban area. Network analysis tool was used to create network dataset and determine new route and closest facility (health institution). Queries were used to provide solutions/answers for questions about some spe- cific entity in the study area extracted from the database created. Basic queries can be either single or multiple criterions. Single query bring out one field result while multi-criterion brings more than one field to generate

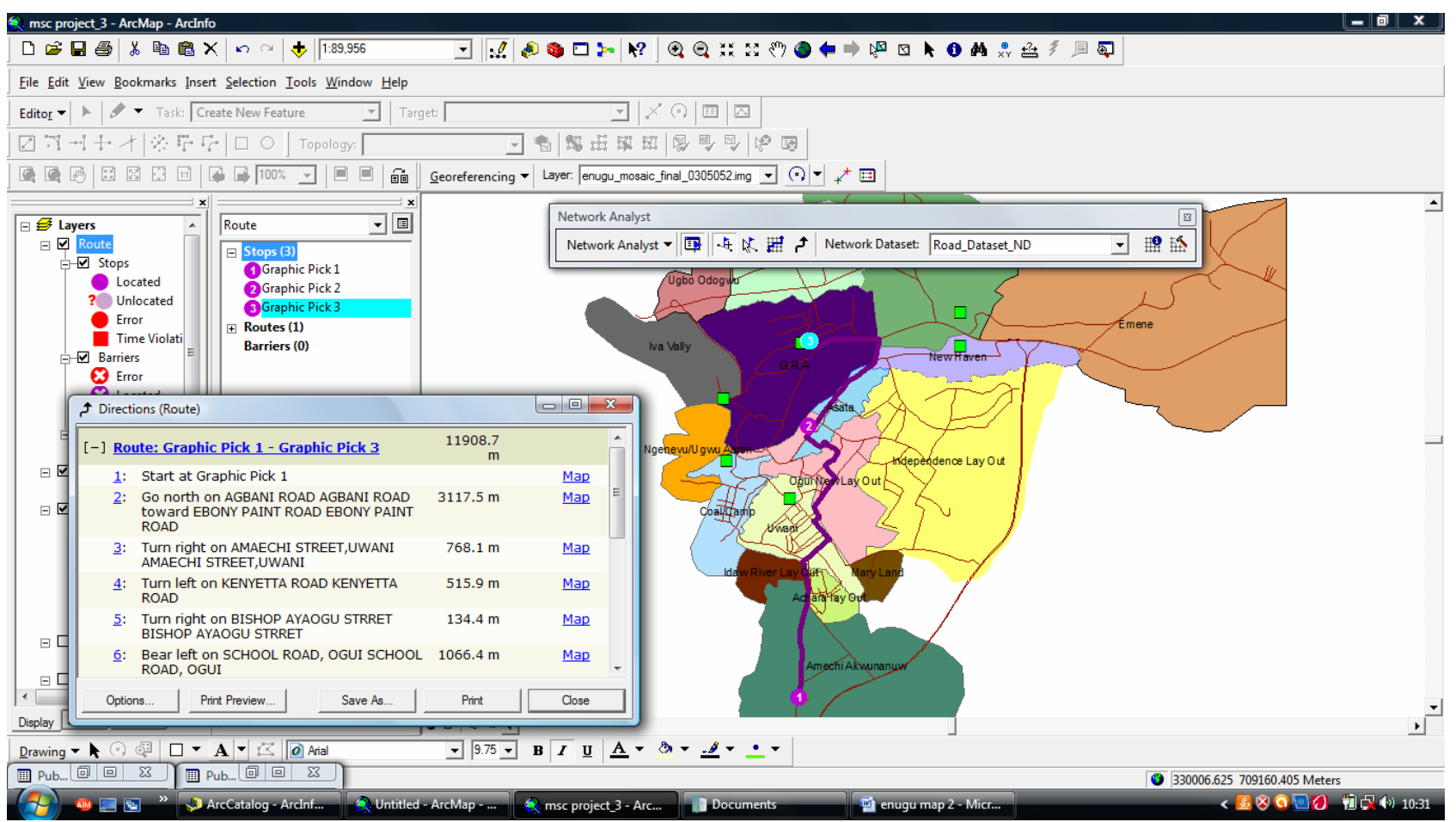

Figure 6. Route from Amechi Awkunanw (Deprived settlement) to ESUT teaching hospital (G.R.A).

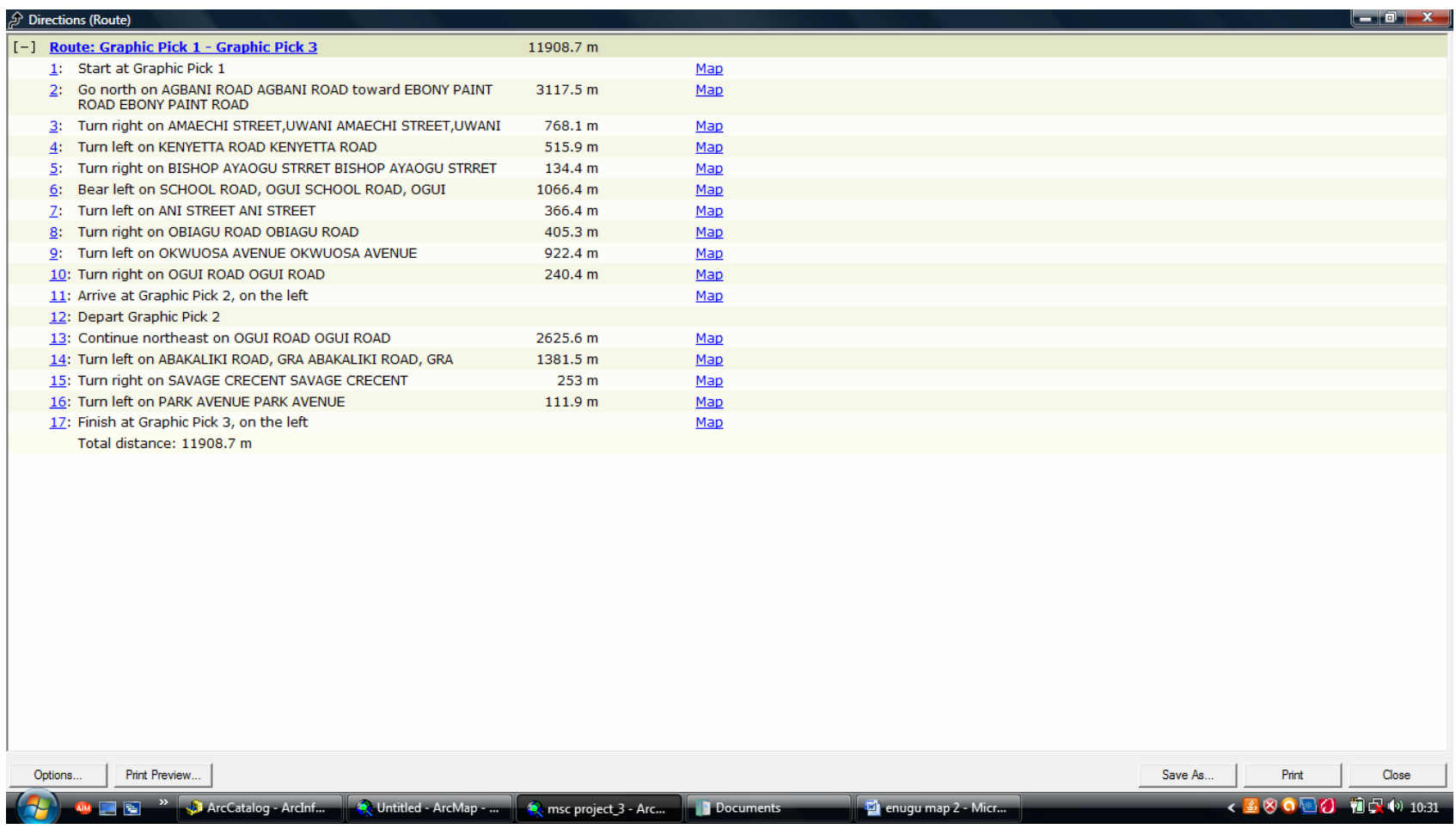

Figure 7. Direction window for route from Amaechi Awkunanw (deprived settlement) to ESUT teaching hospital (G.R.A). 
result. In the study both single and multi criteria queries were used to answer specific questions using query builder for basic commands. Buffering was used in the analysis to measure proximity of the health institutions to the residence areas. According to Longley et al., (2007) [5] given any objects which may include points, lines or areas, a buffer operation build a new object or objects by identifying all areas that are within a certain specified

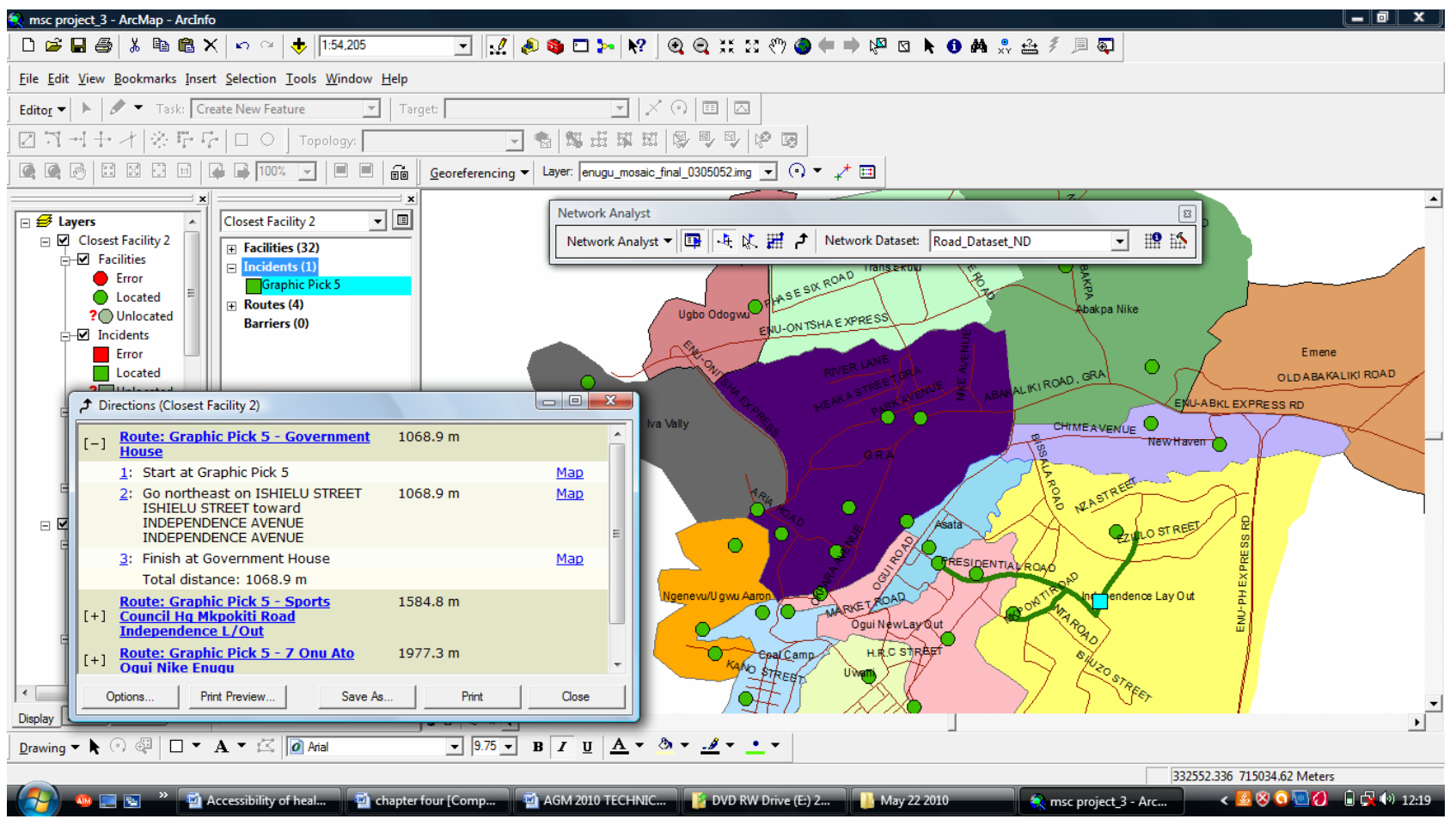

Figure 8. Closest facility around the incident at rangers avenue independence layout.

\begin{tabular}{|c|c|c|c|}
\hline \multicolumn{3}{|c|}{ \$ Directions (Closest Facility 2) } & \multirow[t]{2}{*}{ - 回 $x$} \\
\hline$[-] \underline{\mathbf{R o}}$ & Route: Graphic Pick 5 - Government House & $1068.9 \mathrm{~m}$ & \\
\hline 1: & : $\quad$ Start at Graphic Pick 5 & & Map \\
\hline 2: & $\begin{array}{l}\text { Go northeast on ISHIELU STREET ISHIELU STREET toward } \\
\text { INDEPENDENCE AVENUE INDEPENDENCE AVENUEE }\end{array}$ & $1068.9 \mathrm{~m}$ & $\underline{\text { Map }}$ \\
\hline 3: & $\begin{array}{l}\text { Finish at Government House } \\
\text { Total distance: } 1068.9 \mathrm{~m}\end{array}$ & & $\underline{\text { Map }}$ \\
\hline$[-] \underline{R}$ & Route: Graphic Pick 5 - Sports Council Ha Mkpokiti Road Independence L/Out & $1584.8 \mathrm{~m}$ & \\
\hline $1:$ & : $\quad$ Start at Graphic Pick 5 & & Map \\
\hline 2: & $\begin{array}{l}\text { Go southwest on ISHIELU STREET ISHIELU STREET toward } \\
\text { UPPER PRESIDENTIAL UPPER PRESIDENTIAL }\end{array}$ & $190.6 \mathrm{~m}$ & $\underline{\text { Map }}$ \\
\hline 3: & Make sharp right on UPPER PRESIDENTIAL UPPER PRESIDENTIAL & $503.3 \mathrm{~m}$ & Map \\
\hline 4: & Turn left on MKPOKITI ROAD MKPOKITI ROAD & $890.9 \mathrm{~m}$ & Map \\
\hline 5: & $\begin{array}{l}\text { Finish at Sports Council Hq Mkpokiti Road Independence L/Out } \\
\text { Total distance: } 1584.8 \mathrm{~m}\end{array}$ & & $\underline{\text { Map }}$ \\
\hline [-] Ro & Route: Graphic Pick 5 - 7 Onu Ato Oqui Nike Enuqu & $1977.3 \mathrm{~m}$ & \\
\hline 1: & 1: $\quad$ Start at Graphic Pick 5 & & Map \\
\hline 2: & $\begin{array}{l}\text { Go southwest on ISHIELU STREET ISHIELU STREET toward } \\
\text { UPPER PRESIDENTIAL UPPER PRESIDENTIAL }\end{array}$ & $190.6 \mathrm{~m}$ & $\underline{\text { Map }}$ \\
\hline 3.: & Make sharp right on UPPER PRESIDENTIAL UPPER PRESIDENTIAL & $881.4 \mathrm{~m}$ & Map \\
\hline 4: & Continue on PRESIDENTIAL ROAD PRESIDENTIAL ROAD & $905.3 \mathrm{~m}$ & Map \\
\hline 5: & $\begin{array}{l}\text { Finish at } 7 \text { Onu Ato Ogui Nike Enugu } \\
\text { Total distance: } 1977.3 \mathrm{~m}\end{array}$ & & $\underline{\text { Map }}$ \\
\hline 1: & 1: $\quad$ Start at Graphic Pick 5 & & Map \\
\hline 2: & $\begin{array}{l}\text { Go southwest on ISHIELU STREET ISHIELU STREET toward } \\
\text { UPPER PRESIDENTIAL UPPER PRESIDENTIAL }\end{array}$ & $190.6 \mathrm{~m}$ & $\underline{\text { Map }}$ \\
\hline 3: & Make sharp right on UPPER PRESIDENTIAL UPPER PRESIDENTIAL & $881.4 \mathrm{~m}$ & Map \\
\hline 4: & Continue on PRESIDENTIAL ROAD PRESIDENTIAL ROAD & $1246.7 \mathrm{~m}$ & Map \\
\hline$\underline{5}:$ & Continue on O'CCONOR ROAD O'CCONOR ROAD & $250.3 \mathrm{~m}$ & Map \\
\hline 6: & Finish at Udi Road Asata, Enugu & & Map \\
\hline & Total distance: $2568.9 \mathrm{~m}$ & & \\
\hline Option & Print Preview... & Save As... & Close \\
\hline
\end{tabular}

Figure 9. Direction window for the closest facility around the incidence at rangers avenue independence layout. 
distance of the original objects. This is another type of analysis done in order to carry out proximity analysis of all the Health Institutions within a particular settlement.

\section{Results and Discussions}

\subsection{Results}

The result of the study was presented in form of digital maps, graphic display and attribute tables. Samples of the results include the following:

1) Digital maps showing spatial distribution of healthcare facilities and deprive areas (Figure 5).

2) New route definition from the deprived areas in case of emergency/incidence (Figures 6 and 7).

3) Closest facilities to the areas of incidence (Figures 8 and 9).

4) Query result showing location and ownership of healthcare facility and attribute (Figure 10 and Table 1).

5) Buffering result of healthcare facility in each settlement to show proximity to the facilities (Figure 11).

\subsection{Discussions}

The network analysis was used to measure accessibility of healthcare facility. In the process of the analysis, two settlements were identified as deprived areas with no access to healthcare facility (Figure 6). They are Emene and Amechi-Akwunanuw settlements. They have to travel several kilometres to access the facilities at the city centre. This is quite different from other settlements that have access within a distance of less than $500 \mathrm{~m}$. Various routes were identified and the times taken to access some of these healthcare facilities were as well noted (Figures $\mathbf{7}$ and 8). This will serve for immediate response to an emergency by an ambulance team to avoid traffic delays and save time their-by saving life. It was discovered that people living in the deprive areas have to travel more than $10 \mathrm{~km}$ to access the healthcare facilities (Figure 8). Also in case of an incidence or emergency the closest facility in those deprived areas can only be accessed within a distance of more than $10 \mathrm{~km}$ while other areas can have access to healthcare facility to a distance of 500 m (Figures 9-11).

\section{Conclusions and Recommendation}

This study provides a unique platform to identify and measure accessibility to healthcare facilities in Enugu urban area. All these accessibility measures were used to identify best route and closest facility to access during healthcare emergency. The purpose is to maintain good health and stop the scourge of ill-health due to poor accessibility of health facilities. This poses serious threat in attaining "health for all" and efforts to enhance the lifespan of the people. It is therefore recommended that:

- Healthcare facility should be provided to those deprived areas.

- GIS unit should be a basic component of all agencies responsible for administration of healthcare facility.

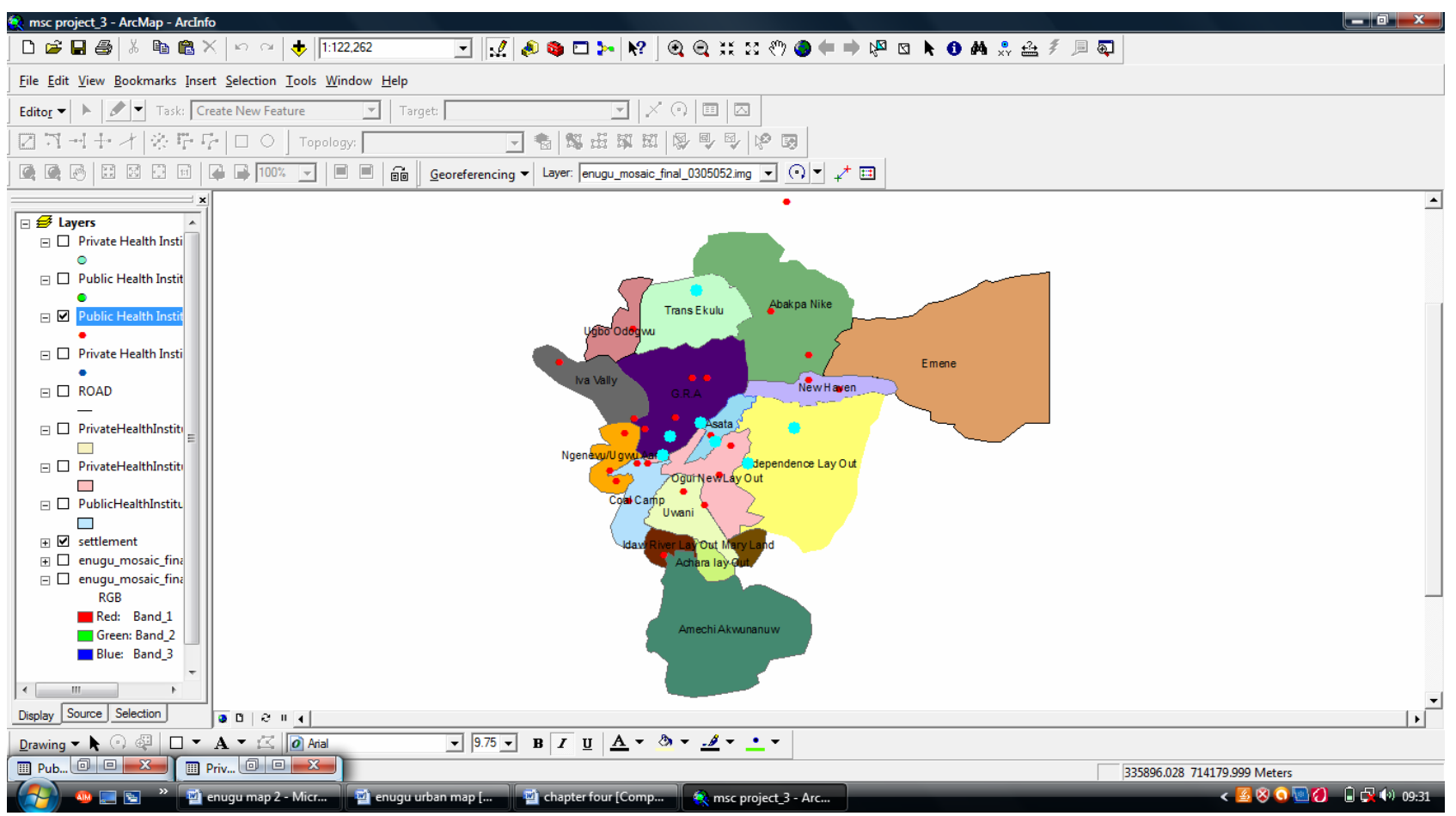

Figure 10. Query result showing government owned health clinic. 
Table 1. Attribute query result of government owned health clinic within the study area.

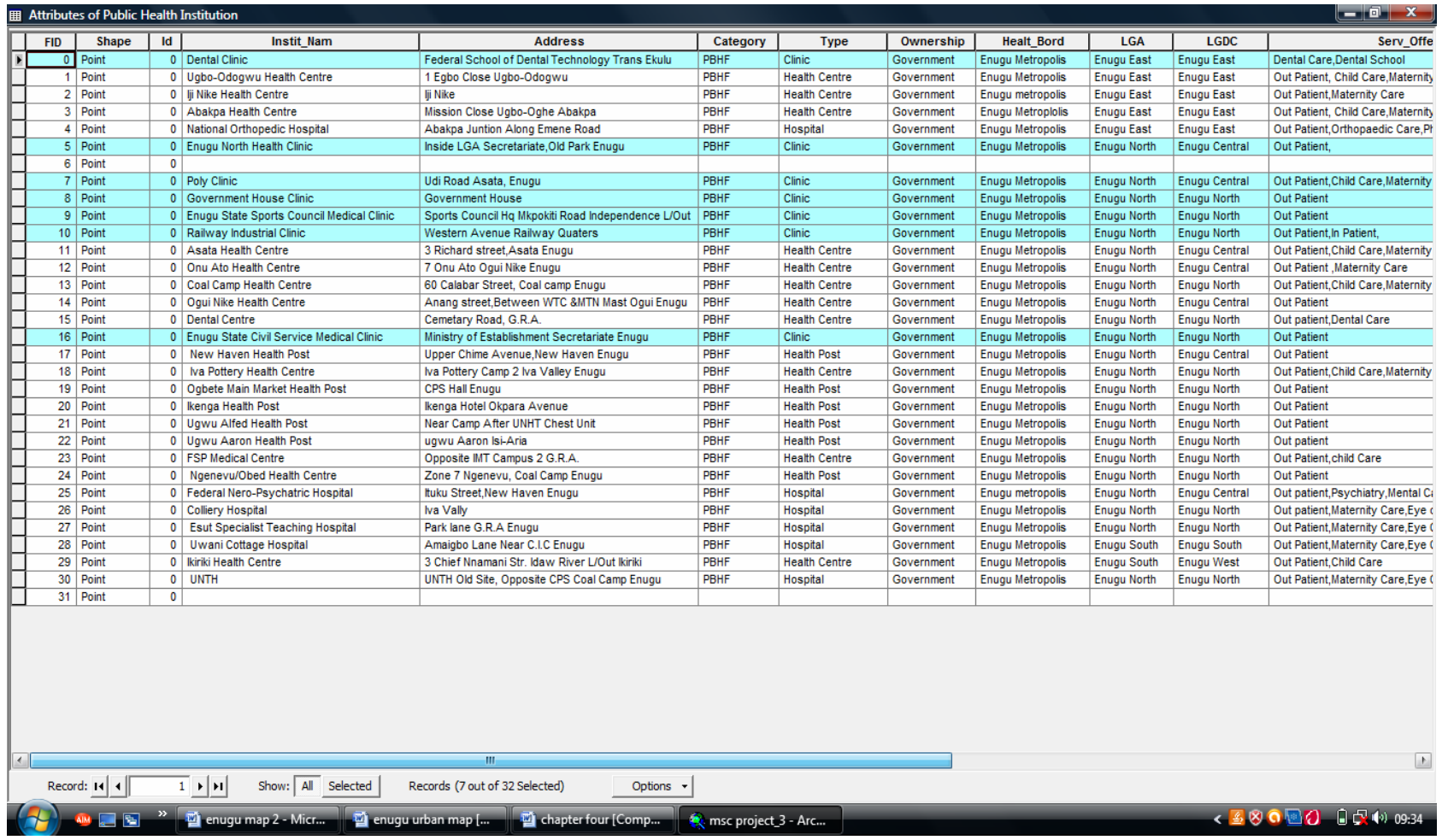

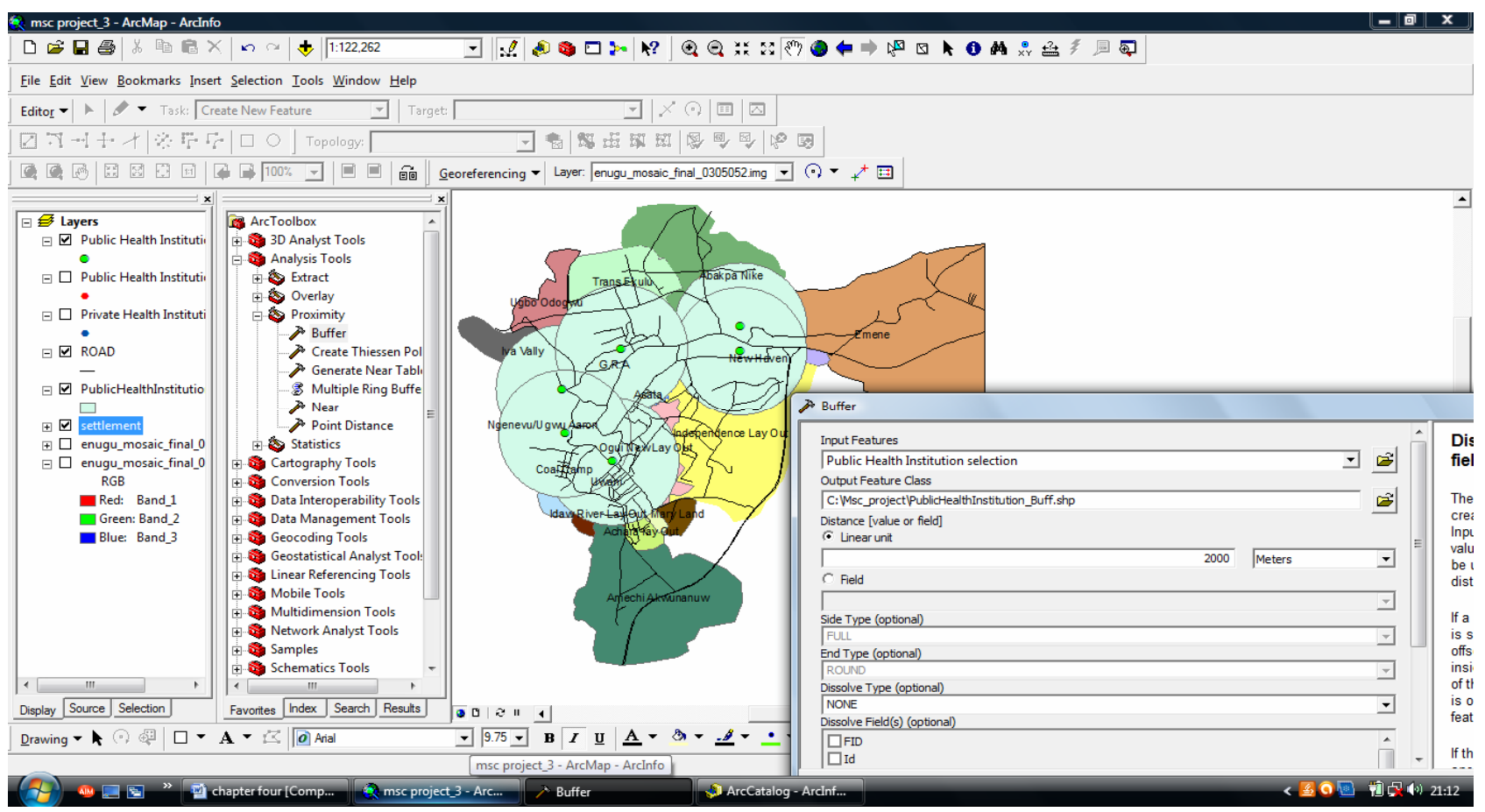

Figure 11. Buffering result of the healthcare facilities to show proximity to the settlements.

- This study could be used as a spatial decision support system for planners and employees of DHS for decisions regarding management of healthcare facilities within the urban area.

\section{REFERENCES}

[1] E. Effiong, "GIS Based Public Healthcare Delivery in Oyo East Local Government Area," Proceedings of the Technical Session of 45th AGM of NIS, 2010, pp. 26-37. 
[2] B. S. C. Uzochukwu, E. Nkoli and E. Soludo, "The District Health System: An Analysis of Policy Development and Implementation,” 2009.

www.research4development.info/searchdatabase.asp

[3] C. G. Eze, “Application of Remote Sensing and GIS for Creation and Management of Enumeration Areas in Enugu State, Nigeria,” Unpublished Ph.D. Dissertation, Nnamdi
Azikiwe University, Awka, 2008.

[4] Federal Republic of Nigeria, "Official Gazette”, No. 2 Vol. 96, Abuja, 2007.

[5] A. P. Longley, F. M. Goodchild, D. J. Maguire and W. D. Rhind, "Geographic Information System and Science," 2nd Edition, John Wiley and Sons Ltd., South Gate, 2007. 